\title{
Role of Iranian EFL Teachers about Using Pronunciation Power Software in the Instruction of English Pronunciation
}

\author{
Abbas Pourhosein Gilakjani ${ }^{1} \&$ Narjes Banou Sabouri ${ }^{2}$ \\ ${ }^{1}$ Lahijan Branch, Islamic Azad University, Lahijan, Iran \\ ${ }^{2}$ Department of Linguistics, Payame Noor University, Tehran, Iran \\ Correspondence: Abbas Pourhosein Gilakjani, 395, Opposite the Emam Hosein Mosque, Valiye Asr Street, \\ Rudsar, Guilan, Iran. Tel: 98-142-623-2762. E-mail: a_p_g48@yahoo.com
}

\author{
Received: September 27, 2013 Accepted: October 14, 2013 Online Published: December 5, 2013 \\ doi:10.5539/elt.v7n1p139 URL: http://dx.doi.org/10.5539/elt.v7n1p139
}

\begin{abstract}
Many studies are related to the use of computer technology in learning and teaching but less work has been done to understand how computer technology users feel about them and how this technology helps in developing teachers' teaching methods. Pronunciation Power software is one of the computer technologies for teaching English pronunciation. This study examined the role of Iranian teachers in utilizing Pronunciation Power software in pronunciation instruction. The researchers used qualitative method consisted of semi-structured interview questions with a volunteer sample of four teachers from an open university in Lahijan, Iran. The researchers answered the research question pertinent to the role of Iranian teachers about utilizing this software in the instruction of pronunciation. Based on the obtained findings, pronunciation power software changed the Iranian teachers' roles from a dispenser of information to a facilitator of information. This change of role gave them more autonomy and greater opportunities in teaching pronunciation.
\end{abstract}

Keywords: role, EFL teachers, pronunciation power software, pronunciation instruction

\section{Introduction}

Pronunciation can always be introduced into the classes by teachers (Rajaduari, 2001) to strengthen the concepts that might have been taught before in pronunciation classes, enhance the importance of pronunciation as a necessary part of the teaching of English as a second/foreign language, provide opportunities for learners to practice and give motivation to learners to use it outside the classroom. Teachers' roles should be changed and the instruction objectives should be altered by methodologies. Teachers should play the role of pronunciation trainers and learners should be proactive learners who take the first step to learn. Instead of paying attention to segmental elements of pronunciation and linguistic competence, supra-segmental elements of pronunciation and communicative competence should be the basic aims of teaching methodologies (Morley, 1991).

Keeping up with innovations is one of the important challenges that teachers face in changing education. A number of researchers have investigated the impact of the use of computer technology on education in different fields. All of these researchers had a similar finding that is pertinent to the efficacy of the use of computer technology in education and how it helps in improving teaching methods and students' knowledge (Frigaard, 2002; Schofield \& Davidson, 2003; Timucin, 2006). One of the significant parts of higher and professional education is technology-enhanced education (Wernet, Olliges, \& Delicath, 2000). Through using computer technology, learners are not only given the opportunity to control their own learning process, but also are provided with ready access to a large amount of information over which the teachers do not have any power or control. The active agents in the process of changes and implementation of new ideas are teachers whose beliefs and attitudes may support or prevent the success of any educational reform like the use of an innovative technology program.

The teacher is a determinant factor to get the learning outcomes because it is the teacher's skills, beliefs, attitudes, perceptions, opinions, personality and knowledge that influence the choices he/she makes about what, when and how to teach by means of using computer technologies (N. Bitner \& J. Bitner, 2002). Therefore, paying attention to the roles of teachers in using computer technologies causes them to be effective users of these technologies. 


\subsection{Role of Teachers in the Use of Computer Technology}

Teachers are the main agents of implementing computer technology. If their roles are not considered in implementing computer technology, it will bring about only limited impacts. Without the participation of teachers, computer technology itself does not make a significant effect on students' achievement. The quality of education can be determined by teachers (Wenglinsky, 2001). Teachers' roles have been divided into five categories: planner, manager, facilitator, guide and participant in computer technology use (Ryba \& Anderson, 1990). As a planner, the teacher makes certain that computers are truly included into the program, organizes the learning environment and urges students to work together. As a manager, the teacher makes certain that students have similar access to computer technology and they use suitable programs based on the students' ability and particular needs.

As a facilitator, the teacher helps students to construct their own knowledge, helps them set their aims for learning and encourages them to examine carefully what they learn. As a guide, the teacher urges students for new learning and persuades students to take part in activities that raise their higher order thinking skills (Ryba \& Anderson, 1990). As a participant, the teacher cooperates with the students to do cognitive learning activities. These categories of teachers' roles imply that integrating computer technology into the classroom changes the teacher's traditional role from a giver of information to a facilitator of information (Ryba \& Anderson, 1990). The purpose of using computer technology is to increase the learning process. A study was done by Iding, Crosby and Speitel (2002). In this study, teachers who used computers for their own personal use were very good at computers and had access to computers at schools and in individual classrooms and were interested in learning more about using computer technology for instructional and educational purposes.

There are different views concerning the role of teacher in relation to computer technology integration. This is the duty of teachers to provide an appropriate learning environment for students who have different experiences, features and skills (MEB, 2008). Teachers should be able to use computer technology effectively in the learning process and they should be a pattern for their students in using the computer technology. According to Prensky (2001), students are defined as natives of the digital world, while teachers are defined as immigrants of the digital world. In order for the immigrants of the digital world (teachers) to have a good connection with the natives (students), they should make changes in their teaching and the subjects they teach. Koehler and Mishra (2009) stated that teachers can play a significant role in shaping classroom uses because education is one of the aspects of classroom uses consisted of the interaction of many information structure rather than a single simple structure. According to Mishra and Koehler (2006), education needs teachers who can present different information structures in different conditions.

\subsection{Role of Computer Technology in English Pronunciation Instruction}

The purpose of using Computer-Assisted Pronunciation (CAP) is to improve English language pronunciation. There are two purposes in using computers to teach English pronunciation: (a) recognizing the student's mistakes in English pronunciation and (b) helping them in correcting these mistakes (Machovikov, Stolyarov, Chernov, Sinclair, \& Machovikova, 2002; Najmi \& Bernstein, 1996). There are a lot of benefits in computer-assisted pronunciation instruction which cannot be found in traditional teaching approaches. Students can have access to unlimited input through using digitized pronunciation software individually and individualized feedback can be provided to them automatically. Many pre-recorded materials can be used by learners through using computers. High quality sound is one of the characteristics of digitized pronunciation software that gives the learner the opportunity to look at articulatory movements used in producing sounds. The other characteristic is that the person can compare his/her sound to that of a native speaker (Neri, Cucchiarini, \& Strik, 2002).

A private, stress-free environment can be provided for students by Computer-Assisted Pronunciation Teaching through which they can access to unlimited input, practice at their own pace and receive feedback through the integration of automatic speech recognition (Hismanoglu, 2006). According to Neri, Cucchiarini, Strik, and Boves (2002), Computer Assisted Pronunciation Teaching (CAPT) methods provide learners with private, stress-free practice with individualized and immediate feedback on pronunciation. Instead of using traditionally printed materials like course information, lecture notes, exercises, quizzes, many pronunciation teachers use Internet-based materials. In place of scattering pronunciation materials in printed handouts to the students in the classrooms, teachers give them to students through the electronic means by changing the way in which students receive phonological input (Hişmanoğlu, 2010).

Internet-based materials have caused pronunciation teachers to enter colorful, natural and interesting teaching materials into their lessons because they offer minimal pairs, tongue twisters, songs, sound animations, step-by step phonetic descriptions and video animations particular to segmental and supra-segmental aspects of English 
pronunciation (Hişmanoğlu, 2010). The investigation of the efficacy of computer-assisted prosody training and its generalization to segmental accuracy and lexical recall has been shown by Hardison (2004). Two experiments in this study were done by the researcher. In the first experiment, a real-time computerized pitch display was utilized in a 3-week training of French prosody training for some English speaking learners. Native French speakers' sentences were applied as feedback to the subjects' initial production. Teachers rated subjects' pre and post-test productions based on the prosody and segmental accuracy and improvements were determined in both areas. In the second experiment, a memory recall task was tested and the findings indicated that the subjects' lexical memory became better through their prosodic memory built by the training. Pitch play was very useful to supra-segmental training and the positive impact of this training on segmental and lexical was determined (Hardison, 2004).

The effectiveness of visual displays like spectrograms is supported by research findings. A method for sensitizing trainee English language teachers from Hong Kong to supra-segmental phonological features in English was investigated by Coniam (2002). He analyzed the authentic spoken material of both Hong Kong English and American English drawn from a local TV through spectrograms. The purpose was to indicate the difference between the syllable-timed Hong Kong English and stress-timed American. Spectrograms helped teachers understand the relationship between a staccato rhythm and the notions of stress and syllable timing. Language teachers were the subjects of this study not learners. These teachers had a different language knowledge background than the language learners CAPT is aimed at (Coniam, 2002).

A group of immigrants in the Netherlands was studied by Neri, Cucchiarini, and Strik (2006a). They were divided into three groups using three types of Dutch instruction: regular instruction with supplemental instruction from an ASR-based Dutch CAPT system, a CAPT system without feedback and no CAPT system. Students showed positive feedbacks to both the ASR-based CAPT systems and the CAPT system without ASR after the training. The group with exposure to the ASR-based CAPT system and the group using CAPT system without ASR showed the largest segmental improvements. Beliefs of many experts toward using CALL (Computer-Assisted Language Learning) system based on ASR technology and on sound pedagogical guidelines were tested by Mich, Neri, and Giuliani (2006). The subjects of this study were young Italian students learning English. A group of students receiving teacher-led instruction with a group receiving ASR-based CALL for individual word pronunciation were compared by the above experts. Both groups of students improved significantly their overall pronunciation quality of both general words and difficult/unknown words. It was indicated that the system was useful in improving the students' pronunciation.

The effectiveness of Talk to Me-English (TTME) was studied by Hincks (2005). TTM-E was developed as one of the complete computer programs for different languages. Feedback provided by this software comprises the following three elements: (a) a 7-point score on pronunciation quality for the utterance; (b) the problematic part of the spoken utterance colored red; (c) visual displays showing the pitch curve and the waveform of the student's utterance together with that of the model speaker. Nine students who used TTM-E on average 12.5 hours and followed a comprehensive 200-hour course in Swedish had actually significant improvement. This improvement was compared with that of a comparable group of 11 students who had not used this system but had used the traditional course in the last term (Hincks, 2005). A computer-based automatic test lasting 10 minutes was used to test the students before and after training and it required students to answer a number of questions on the telephone. When post-tested at the end of the course after 10 weeks, neither group of students indicated important mean improvements in their pronunciation quality. The results exhibited that the students with an initial strong foreign accent improved much more in the experimental group than in the control group and this in turn showed that the less proficient students gain advantage through using with TTM-E (Hincks, 2005). In the experimental group, more proficient students got worse after the training. Then, the findings of the automatic test on a number of utterances read by the students before and after the training were compared. The findings coincided for only 11 of the 24 students and this trend was also found in the human judgment through which the students with more deviant accents improved and the more proficient ones got worse (Hincks, 2005).

\subsection{Features of Pronunciation Power Software}

English Computerized Learning Inc, developed and distributed this system. Four thousand universities, colleges, businesses and schools worldwide are using Pronunciation Power 1 and 2. This software is composed of two levels. The first level is beginning level (PP1) and the second one is intermediate to advanced level (PP2) (Pronunciation Power, 2000). Pronunciation Power 1 comprises over 7000 practice words and thousands of sentences, over 100 hours of training, over 2000 photos and graphics, animated lessons, 1020 listening exercises, hours of exercises for practicing stress, timing, articulation, intonation, and rhythm and four interactive, exciting new games (Pronunciation Power, 2000). Pronunciation Power 2 has all the qualities of PP1 and 52 sounds that 
are essential to speak clearly, ability to compare your sound to the sound of teachers, see how sounds are made by moving the animated side view of the mouth and the tongue, test your listening skill with 650 various sentence exercises, ability to practice pronunciation through interactive and exciting exercises involving 780 sample words and 1040 different sentences (Pronunciation Power, 2000).

\subsection{Application of Pronunciation Power Software}

The goal of this software is to help learners learn the separate sounds of English language. Exercises about phoneme, word and sentence levels and stress are provided by this software. Learners can hear sounds that are pronounced and then they can see the way of producing sounds. This software has also speech analysis and learners can record their sounds and compare them with the pronunciation of their instructors. Fluent speaking skills can be developed through using Pronunciation Power 1 and 2. Pronunciation Power 1 is used by the new learners who have some basic knowledge in grammar and vocabulary. More advanced practice with full sentence intonation and more advanced vocabulary practice are provided by Pronunciation Power 2. The purpose of Pronunciation Power programs is to provide support up to learners' current level and to permit them to progress at their own pace (Pronunciation Power, 2000). Pronunciation Power completes what learners are learning in class and help them increase their pronunciation learning. Teachers can use this program in their classrooms to complete their pronunciation instruction. While learners are progressing on their own, this permits teachers to work with each student separately (Pronunciation Power, 2000).

\subsection{The Comparison of Pronunciation Power Software to Other Software in Teaching English Language Pronunciation}

There is much software for teaching the pronunciation instruction. They are Connected Speech, Streaming Speech, Electronic Dictionaries, World Wide Web, and Pronunciation Power. I briefly explain this software respectively. Protea Textware (2007) have published 3 CD-ROMs that practice pronunciation skills named Connected Speech, suitable for lower intermediate to advanced learners. Their content focuses on suprasegmentals - pause groups, pitch change, word and sentence stress, linking, syllables and the IPA. Their aim is to help learners connect the theory of speech production to the actual speaking process, and ultimately produce natural English. Streaming Speech software, published by Cauldwell (2002), was followed by online courses on pronunciation (Speech in Action). The online courses include many aspects of British and American pronunciation, ranging from intermediate to advanced courses. Extensive linguistic research lies behind the production of Streaming Speech, and all the packages aim at extensive pronunciation practice.

Electronic dictionaries employ technology as a tool in pronunciation instruction. Many publishers have produced CD-ROMs to accompany the hard copies of their dictionaries, which promote "learner autonomy in the acquisition of pronunciation" (Jenkins, 2004). They offer the learner the opportunity to listen to the pronunciation of words in isolation and also in connected speech, to record and listen to the learner's own production and compare with the native pronunciation. Another interesting source of materials on pronunciation instruction is the World Wide Web. Many sites focusing on pronunciation are available online, targeting various levels and age groups. A very interesting site that includes links to a breadth of pronunciation sites is Sunburst Media (n/d), with a page dedicated to pronunciation web resources. It includes sites that practice pronunciation using Shockwave, Quick Time, RealAudio, sound files, text files and also academic resources, phonetics labs and professional organisations (Jenkins, 2004).

Pronunciation Power comprises of 2 CD-ROMs (Pronunciation Power 1 and 2), aiming at helping learners master the individual sounds of the English language. It provides practice at the phoneme, word and sentence levels, with some additional activities on stress. Sounds are introduced, students can hear them pronounced and then they can view videos of how each sound is produced. Speech analysis is also available (wave forms of sounds), and students can also record themselves and compare with the instructor's pronunciation. Pronunciation Power includes a variety of game-like activities and functionalities, such as (a) listen-record-compare, with single words, minimal pairs and full sentences, (b) listening discrimination, (c) vocal-tract cross-section and lip animations, (d) waveform display and comparison, (e) STAIR exercises: stress, timing, articulation, intonation, rhythm, (f) a 40-page manual, (g) on-board illustrated audio dictionary of over 7,000 words with a variety of search keys. Thus, it is a large and fully professional package, entirely devoted to pronunciation training, enjoying a considerable commercial success (Pronunciation Power, 2000).

With the multitude and variety of material and activities it offers, Pronunciation Power is suitable for pronunciation teaching and learning under different conditions and in different settings. Its coverage, in terms of the pronunciation/phonetics syllabus is large, although fast-speech phenomena and accentual differences of English appear to be underrepresented. It has both a lot of traditional textual exposition and the extremely rich 
skill component containing varied activities for practicing listening and speaking (Pronunciation Power, 2000).

\subsection{Statement of the Problem}

English pronunciation is a difficult skill to learn and it is of vital importance for language users. Both Iranian EFL university teachers and learners seem to notice no benefit to it because there is simply no time for such things and overcrowded classes make the situation even less favorable. Some Iranian EFL university teachers have serious problems in both English pronunciation teaching and learning. They are always challenging with the critical problems they face with English pronunciation in their EFL classrooms (Hayati, 2010). One of the best means of improving and solving English pronunciation teaching and learning is to use computer technology. Computer technology provides new possibilities for teaching English pronunciation, creates a successful language environment for both teachers and learners and provides new opportunities for teachers and learners to engage in active communication that facilitates the process of teaching and learning English pronunciation (Hayati, 2010). In light of the potential of technology, Iranian EFL teachers at the university level are using computers that are the replacement of tools of education (e.g., blackboards, chalk, and overhead projectors) because they provide them new and better means of instructional ways and thus improve their English pronunciation teaching and learning. This does not mean that they don't have any problems toward the use of computer technology or are able to use it well or that students' learning has been increased considerably by such technology (Fathiyan, 2004).

Student-centered inquiry can be possible through the interactive nature of the computer technology and this computer capability requires a fundamental change in the role of the teacher. According to Baylor and Ritchie (2002) and Wenglinsky (2001), the teachers should not be the transmitter of information to inactive learners but they should become a guide and a facilitator and provide learners with the tools that they need to research, explore and make meaning. Students can get more power in learning through this change of role and they can have more opportunities to engage in high quality of learning experiences that produce higher order thinking skills like synthesizing, interpreting and hypothesizing (Brett, 1996; Davies \& Crowther, 1995; Dawson, Cavanaugh, \& Ritzhaupt, 2008; Eastment, 1998; Ely \& Plomp, 1986; Hopson et al., 2002; Laurillard, 1995; Ryba \& Anderson, 1990). The researchers examined whether Iranian EFL university teachers' roles are changed if Pronunciation Power software is used.

\subsection{Objective of the Study}

The objective of this study was to examine whether there is a change in teachers' role if Pronunciation Power software is used.

\subsection{Research Question}

Regarding the nature of this study, it responded the following research question:

How do the Iranian EFL university teachers change their role if Pronunciation Power software is used?

\section{Methodology}

\subsection{Research Design}

A qualitative method design was utilized for this study. The qualitative method consisted of interviews with a volunteer sample of four Iranian EFL teachers. The use of qualitative method provided a clear picture of the role of Iranian EFL teachers about utilizing Pronunciation Power software in English pronunciation instruction.

\subsection{Population}

The researchers had talked to four of the faculty members of the English Translation Department at the Islamic Azad University of Lahijan and got their agreement to participate in qualitative aspect of this research. Therefore, these four faculty members had voluntarily participated in the semi-structured interview sessions of data collection processes. Instead of using teachers' real names, Iranian EFL university teachers' pseudonyms were used. They were called P1, P2, P3 and P4.

\subsection{Research Instrument}

Semi-structured interview was used as an instrument to gather data and to investigate the objective of the study. Semi-structured interview questions were conducted with four volunteer participants from the Islamic Azad University of Lahijan. Interviewees were asked questions to gather qualitative data about their roles towards Pronunciation Power software in English pronunciation instruction. The researchers used a high quality small size tape recorder for recording interviews. Tapes were tagged through recording the tape information at the beginning of each interview. After finishing each interview, the transcription of that interview was done. The 
researchers did the coding of the data while doing the transcription. The researchers transcribed using word-by-word transcription. After transcribing each tape, a careful revision of transcription was done to make sure that the transcription matched the actual interview. After revising transcription, interpretation of the interviews was done. In order to eliminate any potential of wrong or inaccurate interpretations of the interviews, the researchers revisited the interviewees and shared with them some of the interpretations. The interviewees were informed at the first meetings that follow-up meetings or interviews might be needed.

\section{Data Analysis}

Qualitative data (semi-structured interview questions) were analyzed according to the qualitative data analysis procedures. According to Miles and Huberman (1994), data analysis requires qualitative researchers to follow this order: reduction of collected data, theme construction or displaying the collected data and theory building or drawing conclusions from the collected data. The researchers followed Miles and Huberman's suggestions in analyzing the data. The researchers reduced the collected data based on (1) simplifying the collected data (2) selecting and focusing on the relevant data (3) eliminating the irrelevant data through changing the written part of the data. After arranging data according to different themes, the researchers looked at the categories based on the role of teachers. After reducing and displaying the data, the researchers drew conclusions. Presenting each part of the interviews that represented the themes gave the researchers the chance to see the relevant data and also to use quotations from the participants input to support arguments.

\subsection{Analysis of Research Question: How Do the Iranian EFL University Teachers Change Their Role When} Pronunciation Power Software Is Used?

Through using Pronunciation Power software, it was indicated that Iranian EFL teachers' classes were learner-centered and were mostly freed from total dependency on teachers, leaned toward putting more responsibility on their learners, persuaded them to cooperate to each other and provided opportunities for teachers to change their roles. Important themes based on the above question are displayed in the following table.

Table 1. Important themes in change of Iranian EFL teachers' role about utilizing Pronunciation Power software

\begin{tabular}{ll}
\hline No. & Themes \\
\hline 1. & Student-centered vs. teacher-centered pedagogy \\
2. & Role of teachers towards using Pronunciation Power software
\end{tabular}

Description: Results of the research question indicated that Iranian EFL teachers changed their role and they preferred student-centered pedagogy.

\subsection{Student-Centered vs. Teacher-Centered Pedagogy}

According to researchers' interviews, the Iranian EFL teachers' teaching roles were teacher-centered, student-centered and a mixture of both. Interviews showed that the Iranian EFL university teachers changed their roles based on their classes. There was a good relationship between students and their teachers. The nature of the relationship between the teachers and their students made both perceive their roles totally different from each other. But almost all Iranian EFL teachers approximately accepted to have student-centered class.

My class was first of all teacher-centered and it depended, for example, if a class had good students I could use it because EFL learners will be more motivated.

My class was mainly student-centered but I couldn't avoid making it teacher-centered in the sense that the students wanted to know what I had for them. The use of Pronunciation Power software made my students see the progress in their language pronunciation and gave them the motivation to allocate more time using it for their pronunciation learning.

My classes were mostly freed from total dependency on me and leaned toward putting more responsibility on my learners.

My students felt more comfortable pronunciation learning from Pronunciation Power software rather than from me who is evaluating them. The use of Pronunciation Power software in my teaching made me easily able to free myself from telling the students everything they needed to know and instead making the students decide what they want to learn about pronunciation and how they learn it. 


\subsection{Teachers' Role towards Using Pronunciation Power Software}

The researchers' interviews displayed that Pronunciation Power software was used in changing the Iranian EFL university teachers' roles as the sources of pronunciation knowledge.

While preparing for classes, my role changed from covering as much information as possible to focusing on making the students see what kind of English pronunciation knowledge is helpful and then try to search for it. P1

I am not the source of pronunciation knowledge alone but the students now see other sources of pronunciation knowledge like the Pronunciation Power software for English language pronunciation learning.

In my idea, Pronunciation Power software is important because it changes my role by raising my confidence and reducing causes of embarrassment and fear of producing the English words.

I can say that the use of Pronunciation Power software freed my students from dependence on one source of pronunciation knowledge to as many as they can find.

P4

\section{Discussion}

In the following section, research question related to the Iranian EFL university teachers' roles is discussed in detail.

\subsection{Research Question: How Do the Iranian EFL University Teachers Change Their Role When Pronunciation} Power Software Is Used?

Iranian EFL teachers' classes were mainly student-centered but they did not avoid making it teacher-centered. This finding is similar to the study of Wozney, Venkatesh and Abrami (2006). The results obtained from this study showed that teachers who liked more student-centered methods integrated computer technologies more than the teachers who preferred teacher-centered methods. The above finding has been also supported by the study of Chen (2004). In this study, teachers supported student-centered method but they also used teacher-centered method. Pronunciation Power software freed Iranian EFL teachers from dependence on one source of pronunciation knowledge to as many as they could find. This finding has been supported by the finding of Sheingold and Hadley (1993). They said that teachers use computer technology in presenting more complex materials to students, allowing them to work more independently not to depend too much on their teachers and finding numerous sources for one teaching material.

The use of Pronunciation Power software made EFL teachers easily free themselves from telling the learners everything they needed to know and instead making them decide what they want to learn about pronunciation and how they learn it. This finding is in accordance with the finding of Chapman (1997). He said that through using computer technology, teacher-centered lectures are moved to more student-centered strategies in which students search for information, analyze data and draw their own conclusions. The above finding is also similar to the study of David (1991). He said that computer technology allows teachers to move from the role of dispenser of knowledge to a facilitator and permits them to motivate their students to become active learners. Teaching method must change from dispensing information to creating activities that engage students' minds and present intricate problems with many solutions.

Iranian EFL university teachers' role changed from teaching the learners to helping them learn the English pronunciation. The role changed from covering as much information as possible to focusing on making the learners see what kind of English pronunciation knowledge is helpful and then try to search for it. This is a finding similar to the fact that when we pay attention to the student-centered method, this does not mean that the teacher does not play any role in the educational program, but rather that the role of the teacher changes from transfer of knowledge to the facilitator of that knowledge (Davies \& Crowther, 1995), authority to facilitator (Kornum, 1992), director of learning to facilitator of learning (Brett, 1996), wise of the stage to guide on the side (Eastment, 1998), transmitter of knowledge to coach the learning and telling everything to facilitating it (Laurillard, 1995). The above finding has also been supported by the study of Mouza (2008). He stated that one of the positive and desirable effects of bringing computer technology into the classroom is the increase in collaboration among teachers and learners. Learners are able to help teachers on computer technology because they have had the time to master while teachers work on directing the instruction. This increases learners' and teachers' meaningful use of computer technology and collaborative participation.

Iranian EFL university teachers used Pronunciation Power software because it provided them with opportunities to make their classrooms become student-centered classrooms instead of teacher-centered classrooms. This finding is consistent with the study of Rice et al., (2001). They studied the use of computer technology by a teacher. They explored how this teacher used computer technology to change his classroom from a traditional 
classroom into a student-centered classroom in which he acts as a facilitator rather than a lecturer. This teacher changed his classroom into a student-centered classroom and helped his students gain new skills in computer technology, collaboration, presentation and self-learning. Pronunciation Power software put more responsibility on learners and improved teachers' pronunciation instruction through changing their roles into student-centered pedagogy. This finding has been supported by the study of Drayton, Falk, Hobbs, Hammerman and Stroud (2010). They emphasized that computer-based classroom improves teacher's instruction and fosters learner's responsibility. They said that computer technology makes better their teaching and encourages student-directed learning.

To sum up, Iranian EFL university teachers:

1) changed their teaching roles from teacher-centered to student-centered,

2) used student-centered pedagogy because it put more responsibility on learners,

3 ) were encouraged to find more than one source of pronunciation knowledge, and

4) played the role of the facilitator of knowledge than dispenser of that knowledge through using Pronunciation Power software.

\section{Conclusion}

This study developed an understanding of how Pronunciation Power software was used in English pronunciation instruction. This study explored the Iranian EFL university teachers' roles about utilizing Pronunciation Power software in English pronunciation instruction. The findings of this study indicated that the Iranian EFL teachers' teaching roles were changed from teacher-centered to student-centered because Pronunciation Power software provided opportunities for teachers to change their classes into student-centered classes instead of having a teacher-centered one. Pronunciation Power software changed the Iranian EFL teachers' role from the dispenser of knowledge to a facilitator and guide to find that knowledge and motivated their students to become active learners. Pronunciation Power software put more responsibility on learners not teachers. Iranian EFL university teachers improved their pronunciation instruction through changing their roles into student-centered pedagogy. This study has hopefully contributed to the growing body of knowledge in the field of using Pronunciation Power software in the instruction of English pronunciation. The outcomes of this study optimistically provided a starting point for making changes at the Islamic Azad University of Lahijan towards using Pronunciation Power software in the instruction of English pronunciation.

\section{Acknowledgements}

We thank Seyedeh Masoumeh Ahmadi, Alizadeh and Babaee for their extensive and insightful discussions and comments on the paper.

\section{References}

Baylor, A. L., \& Ritchie, D. (2002). What factors facilitate teacher skill, teacher morale, and perceived student learning in technology-using classrooms? Computers and Education, 39(4), 395-414.

Bitner, N., \& Bitner, J. (2002). Integrating Technology into the Classroom: Eight Keys to Success. Journal of Technology and Teacher Education, 10(1), 95-100.

Brett, P. (1996). Using multimedia: An investigation of learners' attitudes. Computer Assisted Language Learning Journal, 9, 191-212.

Cauldwell, R. (2002). Streaming Speech: Listening and Pronunciation CD-ROM. Birmingham: Speechinaction.

Chapman, D. W. (1997). Improving instructional practice: The teacher's dilemma. In J. Lynch, C. Modgil, \& S. Modgil (Eds.), Innovations in delivering primary education, Volume 3 of the Education and Development: Tradition and Innovation series. London: Cassell Publishers.

Chen, C. (2004). Why do teachers not practice what they believe regarding technology integration? Journal of Educational Research, 102(1), 65-75.

Coniam, D. (2002). Perceptions of a multimedia syllabus - making the demands of a performance test more accessible. System, 31, 55-70.

David, J. L. (1991). Restructuring and technology: Partners in change. Phi Delta Kappan, 73(1), 37-40, 78-82.

Davies, M., \& Crowther, D. (1995). The benefits of using multimedia in higher education: Myths and realities. Active Learning, 3, 3-6.

Dawson, K., Cavanaugh, C., \& Ritzhaupt, A. (2008). Florida's EETT Leveraging Laptops Initiative and its 
impact on teaching practices. University of North Carolina at Wilmington, 41(2), 143-159.

Drayton, B., Falk, J. K., Stroud, R., Hobbs, K., \& Hammerman, J. (2010). After installation: Ubiquitous computing and high school science in three experienced, high-technology schools. Journal of Technology, Learning and Assessment, 9(3).

Eastment, D. (1998). English language teaching and the new technology: The next five years. Retrieved from http://www.eastment.com/lebanon.htm

Ely, D., \& Plomp, T. (1986). The promises of educational technology: A reassessment. International Review of Education, 32, 231-250.

Fathiyan, M. (2004). The study of a desired pattern of computer literacy for Iranian teachers. The University of Science and Industry, the Ministry of Education, the Design and Develop and Application Office of Information and Communication Technology.

Frigaard, A. (2002). Does the computer lab improve student performance on vocabulary, grammar, and listening comprehension? ERIC Document Reproduction Service No. ED476749.

Hardison, D. (2004). Generalization of computer-assisted prosody training: Quantitative and qualitative findings. Language Learning and Technology, 8(1), 34-52.

Hayati, A. M. (2010). Notes on Teaching English Pronunciation to EFL Learners: A Case of Iranian High School Students. English Language Teaching, 3(4), 121-126.

Hincks, R. (2005). Computer support for learners of spoken English. Unpublished doctoral dissertation, KTH Stokholm, Sweden.

Hişmanoğlu, M. (2006). Current Perspectives on Pronunciation Learning and Teaching. Journal of Language and Linguistic Studies, 2(1).

Hişmanoğlu, M. (2010). Online Pronunciation Resources: Hobbies or Fobbies of EFL Teachers? IJONTE, 1(2), 40-53.

Hopson, M. H., Simms, R. L., \& Knezek, G. A. (2002). Using a technology-enriched environment to improve higher-order thinking skills. Journal of Research on Technology in Education, 34(2), 109-119.

Iding, M. K., Crosby, M. E., \& Speitel, T. (2002). Teachers and technology: Beliefs and practices. International Journal of Instructional Media, 29(2), 153-170.

Jenkins, J. (2004). Research in Teaching Pronunciation and Intonation. Annual Review of Applied Linguistics, 24, 109-125.

Koehler, M. J., \& Mishra, P. (2009). What is technological pedagogical content knowledge? Contemporary Issues Technol. Teach. Educ., 9(1), 60-70.

Kornum, L. (1992). Foreign language teaching and learning in a multimedia environment. The CALICO Journal, 10(3), 65-76.

Laurillard, D. (1995). Multimedia and the changing experience of the learner. British Journal of Educational Technology, 26(3), 179-189.

Machovikov, A., Stolyarov, K., Chernov, M., Sinclair, I., \& Machovikova, I. (2002). Computer-based training system for Russian word pronunciation. Computer Assisted Language Learning, 15(2), 201-214.

MEB. (2008). Teacher Qualifications. Ankara: State Books Directorate.

Mich, O., Neri, A., \& Giuliani, D. (2006). The effectiveness of a computer assisted pronunciation training system for young foreign language learners. Proceedings of CALL, 135-143.

Miles, M. B., \& Huberman, A. M. (1994). Qualitative data analysis: A sourcebook of new methods. Thousand Oaks, CA: Sage Publications.

Mishra, P., \& Koehler, M. J. (2006). Technological Pedagogical Content Knowledge: A Framework for Teacher Knowledge. Teach. Col. Rec., 108(6), 1017-1054.

Morley, J. (1991). The pronunciation component in teaching English to speakers of other languages. TESOL Quarterly, 25(1), 51-74.

Mouza, C. (2008). Learning with laptops: Implementation and outcomes in an urban, underprivileged school. Journal of Research on Technology in Education, 40(4), 447-472. 
Najmi, A., \& Bernstein, J. (1996). Speech recognition in a system for teaching Japanese. Journal of the Acoustical Society of America, 100(4).

Neri, A., Cucchiarini, C., \& Strik, H. (2002). Feedback in computer assisted pronunciation training: When technology meets pedagogy in Proceedings of CALL Conference "CALL professionals and the future of CALL research", Antwerp, Belgium, (pp. 179-188).

Neri, A., Cucchiarini, C., \& Strik, H. (2006a). Selecting segmental errors in L2 Dutch for optimal pronunciation training. International Review of Applied Linguistics, 44, 357-404.

Neri, A., Cucchiarini, C., Strik, H., \& Boves, L. (2002). The Pedagogy-Technology interface in Computer Assisted Pronunciation Training. Computer Assisted Language Learning, 15(5), 441-467.

Prensky, M. (2001). Digital Natives, Digital Immigrants. J. Horizon, 9(5).

Pronunciation Power. (2000). English Computerized Learning Inc., Edmonton. Publication Inc.

Protea Textware. (2007). Connected Speech. Retrieved from http://www.proteatextware.com.au/shopexd.asp?id=103\&bc=yes?id=103

Rajadurai, J. (2001). An Investigation of the Effectiveness of Teaching Pronunciation to Malaysian TESOL Students. Forum, 39(3), 10-15.

Rice, M. L., Wilson, E. K., \& Bagley, W. (2001). Transforming learning with technology: Lessons from the field. Journal of Technology and Teacher Education, 9(2), 211-230.

Ryba, K., \& Anderson, B. (1990). Learning with computers: Effective teaching strategies. Euguen, OR. International Society for Technology in Education.

Schofield, J. W., \& Davidson, A. L. (2003). The impact of internet use on relationship between teachers and students. Mind, Culture, and Activity, 10(1), 62-79.

Sheingold, K., \& Hadley, M. (1993). Commonalities and distinctive patterns in teachers' integration of computers. American journal of education, 101(3), 261-315.

Timucin, M. (2006). Implementing CALL in the EFL context. ELT Journal, 60(3), 262-271.

Wenglinsky, H. (2001). Flunking ETS: How teaching matters. Education Matters, 1(2), 75-78. Princeton, NJ: Policy Information Centre. Educational Testing Service.

Wernet, S., Olliges, R., \& Delicath, T. (2000). Post course evaluation of Web CT (Web Course Tools) classes by social work students. Research on Social Work Practice, 10(4), 487-504.

Wozney, L., Venkatesh, V., \& Abrami, P. C. (2006). Implementing computer technologies: Teachers' perceptions and practices. Journal of Technology and Teacher Education, 14(1), 173-207.

\section{Appendix}

Semi-Structured Interview Questions

The following questions are meant to elicit information about the student-centered and teacher-centered pedagogy and teachers' role towards using Pronunciation Power software in the instruction of English pronunciation.

Questions:

1. Which one do you prefer?

A. student-centered pedagogy

B. teacher-centered pedagogy

2. What do you think about your teaching role when using Pronunciation Power software in the instruction of pronunciation?

\section{Copyrights}

Copyright for this article is retained by the author(s), with first publication rights granted to the journal.

This is an open-access article distributed under the terms and conditions of the Creative Commons Attribution license (http://creativecommons.org/licenses/by/3.0/). 